\title{
VPRAŠANJA IDENTITET, MIGRACIJ IN TRANSKULTURNOSTI: PRIMER PESNICE CVETKE LIPUŠ
}

\author{
Tanja ŽIGON! Vesna KONDRIČ HORVAT", Boštjan UDOVIČ"
}

COBISS 1.01

\section{IZVLEČEK \\ Vprašanja identitet, migracij in transkulturnosti: Primer pesnice Cvetke Lipuš}

Pesnica Cvetka Lipuš je mednarodno uveljavljena in večkrat nagrajena pesnica, rojena na avstrijskem Koroškem. Po študiju v Avstriji je odšla v Združene države Amerike, nato pa se je po več kot desetletju bivanja čez lužo vrnila in se ustalila v Salzburgu. Doslej je izdala sedem pesniških zbirk in je ena izmed najpomembnejših ambasadork slovenske kulture v tujini. Svoje pesniške misli preliva na papir izključno v slovenščini, svojem prvem jeziku, medtem ko sta nemščina in angleščina jezika njene izobrazbe in poklicnega življenja. V prispevku se avtorji sprašujejo, kako se migracije in trije kulturni krogi, ki jo spremljajo, odražajo v njenem življenju in delu.

KLJUČNE BESEDE: Cvetka Lipuš, slovenska književnost, narodna manjšina, izseljenstvo, migracije, transkulturnost

\section{ABSTRACT}

Questions of Identity, Migrations and Transculturality: The Case of the Poet Cvetka Lipuš Cvetka Lipuš is an internationally acclaimed multi-award-winning poet born in the Carinthia region in Austria. After graduating from university in Austria, she moved to the United States. After more than a decade of living across the Atlantic, she returned and settled in Salzburg. She has published seven poetry collections to date, and is one of the most important ambassadors of Slovenian culture abroad. She writes her poetry only in her mother tongue, i.e. Slovene, while she has also studied and worked in German and English. In this paper, we examine how her migrations and the three cultures are reflected in her life and work.

KEY WORDS: Cvetka Lipuš, Slovenian literature, national minority, emigration, migrations, transculturality

Dr. znanosti, izredna profesorica za prevodoslovje, Filozofska fakulteta Univerze v Ljubljani, Aškerčeva 2, SI-1000 Ljubljana; tanja.zigon@ff.uni-lj.si

\| Dr. znanosti, redna profesorica za novejšo nemško književnost, Filozofska fakulteta Univerze v Mariboru, Koroška cesta 160, SI-2000 Maribor; vesna.kondric@uni-mb.si

III Dr. znanosti, izredni profesor s področja diplomacije (korespondenčni avtor), Fakulteta za družbene vede Univerze v Ljubljani, Kardeljeva ploščad 5, SI-1000 Ljubljana; bostjan.udovic@ fdv.uni-lj.si - Prispevek je nastal v sklopu raziskovalnih programov »Slovenija in njeni akterji v mednarodnih odnosih in evropskih integracijah«, št. P5-0177, in »Medkulturne literarnovedne študije«, št. P6-0265, ki ju sofinancira Javna agencija za raziskovalno dejavnost Republike Slovenije iz državnega proračuna. Za sodelovanje se avtorji zahvaljujejo Cvetki Lipuš in anonimnima recenzentoma, ki sta pripomogla k izboljšanju članka. 


\section{UVOD IN OPREDELITEV RAZISKOVALNEGA PROBLEMA}

Mednarodno uveljavljena pesnica, dobitnica nagrade Prešernovega sklada leta 2016, ${ }^{1}$ koroška Slovenka Cvetka Lipuš, je trenutno nedvomno ena najpomembnejših in najaktualnejših ambasadork slovenske kulture $v$ tujini. Rojena je na avstrijskem Koroškem, na Dunaju in v Celovcu je študirala primerjalno književnost in sinologijo, sredi devetdesetih let prejšnjega stoletja pa je zapustila staro celino ter se z namenom študija bibliotekarstva in informacijskih znanosti kot tudi zaradi poklicne poti za več kot desetletje ustalila v Združenih državah Amerike. Pred desetletjem se je vrnila v Avstrijo, v Salzburg, kjer danes živi in dela. Cvetka Lipuš je »mobilna« umetnica, pri kateri (kot pri mnogih drugih) so migracijski procesi, tako Repič (2006: 37-52), odvisni od njenih »povsem osebnih izkušenj, odločitev in strategij ter po drugi strani od zunanjih (družbenih, političnih in ekonomskih) dejavnikov«.

Takšni posamezniki še bolj aktivno sodelujejo v procesih »oblikovanja, spreminjanja in ohranjanja družbenih kategorij ter osebnih in skupinskih identifikacij«, ki sicer potekajo v vseh okoljih in kadarkoli, vendar pa so "zlasti opazni v migracijskih procesih, ki pri posameznikih dodatno sproščajo točke identifikacij in omogočajo, pogosto pa celo zahtevajo, identitetne spremembe in njihove redefinicije«. Tako tudi transnacionalne migracije niso izjemen ali izreden pojav, ki bi bistveno in popolnoma zaznamoval posameznika, temveč pojav, ki posamezniku »omogoča bodisi obstojnost bodisi (pre)oblikovanje lastnih identitet ter povezovanje $v$ nove skupnosti in družbene mreže«, pri čemer gre predvsem za redefinicijo nacionalnih identitet, pomen pripadnosti in identifikacij z (izvirno) domovino ter identitetne spremembe. (Repič 2006: 37) Tako lahko hitro ugotovimo, da Cvetka Lipuš, čeprav v strogo geografskem smislu nikoli ni živela v Sloveniji, piše izključno v slovenščini in velja za slovensko pesnico. Sama bi, če bi bila postavljena pred odločitev, katero zastavo izobesiti na svojem domu, brez oklevanja izbrala slovensko (Pišek 2016). Rečemo lahko, da Cvetka Lipuš živi dve domovini. Vprašanje, ki se postavlja, pa je, kako je z njenim (samo)identificiranjem.

Kot ugotavlja Repič (ibid.), sta v življenju migrantov prisotni večplastnost in spremenljivost identifikacij. Tako se pri Cvetki Lipuš na primer lahko vprašamo, ali se (samo) identificira kot pripadnica slovenske narodne skupnosti na avstrijskem Koroškem ali pa je, glede na to, da je živela v ZDA, njena (samo)identifikacija izseljenska? V slednjem primeru je vprašanje lahko tudi, ali gre za avstrijsko ali slovensko izseljenko? In, navsezadnje, ali moramo na problematiko pogledati širše in se vprašati, ali je njena identifikacija povsem drugačna in presega ustaljene binarne kategorije, je fluidnejša, predvsem pa, ali jo lahko razumemo le »v procesu razlikovanja, nenehne vzpostavitve lastne identitete v razmerju do drugih, vzpostavitve sebstva v razmerju do drugih sebstev in do drugosti v lastnem jazu« (Jurić Pahor 2015: 184). Ta vprašanja so osrednje vodilo pričujoče razprave.

1 Leta 2008 je bila z zbirko Obleganje sreče ter leta 2015 z zbirko Kaj smo, ko smo tudi med petimi finalisti za Veronikino nagrado, ki jo podeljujejo za najboljšo pesniško zbirko leta. Svoj prostor je pesnica našla tudi v pregledih novejše slovenske lirike (Strutz 1998: 224; Poniž 2001: 315-317; Novak Popov 2007: 376-377). 
Klasična teorija gradnje identitete, ki temelji predvsem na binarnih konceptih (mi vs. drugi), bi Cvetko Lipuš identitetno gotovo označila kot pripadnico manjšinske (torej zamejske) skupnosti in ji zato pripisala določene (vnaprej znane, stereotipizirane, morda celo s predsodki pogojene) značilnosti (prim. Hall 1996; Zupančič, Arbeiter 2016; Arbeiter, Udovič 2017; Kočan, Arbeiter 2019). Na drugi strani pa bi migracijske študije njeno identiteto gradile predvsem na podlagi njenih geografskih (in družbenih) premikov. V obeh primerih bi Cvetka Lipuš takšno definiranje identitet zavrnila. $\checkmark$ prvem zato, ker z manjšinsko skupnostjo že dvajset let nima nobenega stika, v drugem pa zato, ker njene geografske selitve niso bile pogojene z identifikacijo oziroma iskanjem identitete, temveč je migrirala predvsem na podlagi osebne (ekonomske) odločitve (prim. Pišek 2016). Iz povedanega izhaja, da je najprimernejši koncept za razumevanje identitete Cvetke Lipuš teoretski okvir transkulturnosti, ki se je v Evropi spričo razprav $v$ spremenjenih kulturnih konceptih - takrat so se intenzivirali globalizacijski in migracijski procesi - uveljavil v devetdesetih letih prejšnjega stoletja.

Wolfgang Welsch (1997: 78; 1999: 196) je tako uvedel koncept transkulturnosti, ki ga razume kot prelivanje elementov identitet(e) med kulturnimi mrežami (posameznika), znotraj katerih se elementi identitete delno ali v celoti prekrivajo, lahko pa se tudi razlikujejo. A medtem ko Welsch kljub nekaterim pomislekom ne preseže tradicionalnega kulturnega koncepta in se ozira v nacionalno preteklost in na odnos do (nacionalne) kulture, pa novejše raziskave binarne kategorije vzpostavljanja (kulturnih) identitet nadomeščajo $s$ konceptom prehodnih identitet (več o tem Jurić Pahor 2012a, 2012b; 2015a, 2015b; 2018; Zadel 2016: 71-101). Bistvo sodobne identitete, kot kažejo koncepti, nastali v okviru kulturoloških in postkolonialnih študijev, je ravno v njenem revidiranju, (samo)zanikovanju in redefiniranju (Hall 1996; Bhabha 2000; Jurić Pahor 2012a). Različne identitete namreč posegajo po različnih kulturnih tradicijah in so rezultat zapletenih identifikacij in križanj, tako da se subjektova identiteta nenehno »preklaplja« (Jurić Pahor 2015: 184). Aplikacija razumevanja transkulturnosti na primeru Cvetke Lipuš je prikazana na Sliki 1.

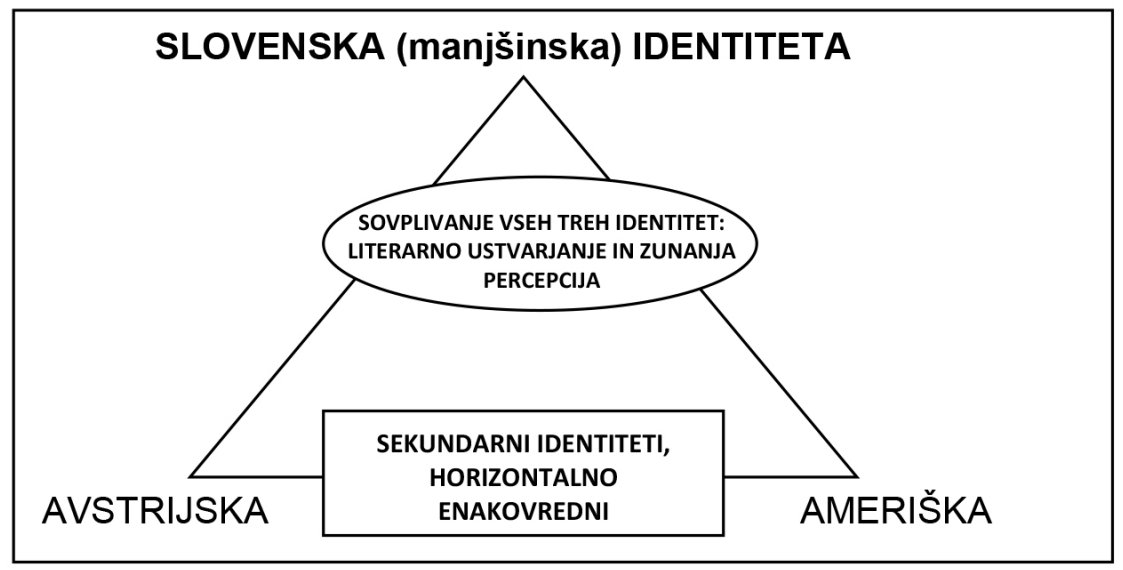

Slika 1: Transkulturnost pesnice Cvetke Lipuš (vir: lastni prikaz). 
Transkulturnost Cvetke Lipuš se tako kaže s prekrivanjem treh identitet: ${ }^{2}$ manjšinske identitete koroške Slovenke, identitete avstrijskega okolja, v katerem je Cvetka Lipuš prešla primarno in sekundarno socializacijo, ter identitete njenega življenja $v$ Združenih državah Amerike, ki je bila povezana predvsem z osebnimi in ekonomskimi razlogi. Trojnost identitet Cvetke Lipuš se v transkulturnosti ne pojavlja v enakovrednih delih. Manjšinska identiteta, ki je pesnico oblikovala v okviru njene osebne formacije, je bila prvi pogoj za oblikovanje družbenih kategorij in osebnih ter skupinskih identifikacij, ki zaznamujejo njeno sekundarno in terciarno identiteto. To pa pomeni, da Cvetka Lipuš prihaja do fluidnih prehajanj, in čeprav že dvajset let nima stika z manjšino na Koroškem, jo identifikacija z njo zaradi preteklih socializacijskih vzorcev in praks še vedno deloma zaznamuje in uokvirja. ${ }^{3}$

Vse povedano nas vodi do dveh raziskovalnih vprašanj, ki jih raziskujemo v pričujočem članku, in sicer:

R1: Kako se transkulturnost, ki je tudi posledica stalnih migracij, kaže pri Cvetki Lipuš oziroma kako se pesnica sooča s tremi identitetami, ki jo določajo, in kako kombinacija treh identitet in treh domovin vpliva na njeno ustvarjanje?

R2: Ali pesnica Cvetka Lipuš v svojem literarnem ustvarjanju zavestno poudarja slovensko komponento?

Ugotoviti želimo, kako močan vpliv imajo različni kulturni krogi, $v$ katerih se giblje, pravzaprav njene identitete, ki jih združuje v svoji biti, na literarno ustvarjanje, hkrati pa tudi, ali se pri avtoričinem ustvarjanju identitete prelivajo iz ene v drugo, se dopolnjujejo ali si morda celo nasprotujejo; ter, če pride do slednjega, kako se pesnica »spopada« (če se) s tovrstnimi intrapersonalnimi izzivi. Navedeno ni pomembno le zaradi ugotavljanja odnosa med identitetami posameznika, ampak tudi zaradi umeščanja teh spoznanj $v$ sistem sposobnosti države ( $v$ našem primeru Slovenije), da individualno identiteto »izkoristi« za krepitev kolektivne identitete in prisotnosti v tretjih državah. (Prim. tudi Lukšič Hacin, Toplak 2012: 107-117; Durnik, Gombač 2012: 119-133; Valentinčič 2016: 153-166: Durnik 2017: 103-118; Žigon 2018: 127-145.)

Prispevek je sestavljen iz treh med seboj povezanih delov. Uvodu in orisu problematike sledi kratek prikaz pesničinega ustvarjanja, temu pa analiza zastavljene problematike. Pri analizi smo uporabili dve dopolnjujoči se metodi, in sicer analizo dostopnih primarnih (predvsem njena objavljena lirika) in sekundarnih virov (intervjuji in javna pojavljanja Cvetke Lipuš v slovenskih medijih) ter kombinacijo polstrukturiranega in nestrukturiranega intervjuja (pogovori), ki smo ga avtorji članka opravili s Cvetko Lipuš (v slovenščini). Vprašanja smo avtorji pesnici postavljali ob več

2 O identitetnih vprašanjih prim. Milharčič Hladnik (2007: 31-46; 2015: 171-182); Repič (2010: 121-134); Hoerder (2012: 97-105); Žitnik Serafin (2011: 35-45; 2014: 31-42) in Lukšič Hacin (2016: 79-91).

3 Pri tem moramo poudariti, da je uokvirjanje identitete zaradi primarnega in sekundarnega socializacijskega procesa veliko rahlejše, kot bi bilo samodefiniranje identitete. 
priložnostih, predvsem ob neformalnih druženjih, komunicirali pa smo tudi po elektronski pošti. ${ }^{4}$ Analizi sledi zaključek, $v$ katerem so povzeti odgovori na raziskovalna vprašanja ter podani predlogi za nadaljnje raziskovanje omenjene problematike.

\section{CVETKA LIPUŠ NA PARNASU SLOVENSKE KNJIŽEVNOSTI}

Cvetka Lipuš je začela pisati že v gimnaziji. Nekaj njenih pesmi so natisnili v Dijaškem glasu in v literarni prilogi časnika Wiener Zeitung. Sredi osemdesetih let je $v$ antologiji sodobne slovenske lirike na Koroškem z naslovom V lunini senci (1985) objavila tudi svojo poezijo. Poleg tega je redno objavljala tudi v slovenskem (koroškem) glasilu Mladje, ki ga je leta 1960 začel izdajati njen oče Florjan Lipuš, v devetdesetih letih prejšnjega stoletja pa je z Majo Haderlap in s Fabjanom Hafnerjem sama prevzela njegovo uredniško taktirko. ${ }^{5}$ Avtorica je doslej izdala sedem samostojnih pesniških zbirk, prve tri so izšle v Celovcu, druge pa v Ljubljani, tri med njimi so nastale v Pittsburghu. Njene pesmi, ki jih piše izključno $v$ slovenščini, so prevedene $v$ številne jezike, med drugim v nemščino, angleščino, italijanščino, srbščino, češčino, slovaščino, bolgarščino, francoščino in madžarščino, kar poleg pesničine biografske zgodbe in različnih krajev nastanka in izida pesmi prav tako kaže na transkulturno razsežnost njenega ustvarjanja. $V$ angleščino je prevedena tudi že naslednja zbirka, ki še čaka na izid in bo tako v obeh jezikih (tj. slovenščini in angleščini) skoraj hkrati izšla leta 2020. Cvetka Lipuš pravi, da v slovenščini piše predvsem zato, ker je ta emocionalno njen prvi jezik, s katerim jo povezujejo močnejša čustva kot z drugimi jeziki (Pišek 2016), ki jo spremljajo. Čeprav tega nikjer eksplicitno ne poudarja, na velikih literarnih dogodkih nikoli ne pozabi povedati, da je slovenska pesnica. ${ }^{6}$

Pesmi Cvetke Lipuš izdajajo bivanjski element posameznika, razpetega med domačim slovenskim jezikom, nemškim jezikom okolja in angleškim jezikom, ki je postal njen jezik izobraževanja in komunikacije v ZDA, vseeno pa, kot to velja za leta 2016 nagrajeno zbirko Kaj smo, ko smo, v njih »ni čutiti zamejske bolečine niti patološke zavezanosti rodni pokrajini, še več, tujina je [avtorici] le ena od postankov, ki ponuja dvoje optimalnih rešitev: ostati ali vrniti se« (Vincetič 2015: 764).

4 Vsa mesta, ki v besedilu niso posebej označena, so povzeta iz osebnih pogovorov/intervjujev z avtorico.

5 Mladim ustvarjalcem je tako uspelo umetnost na avstrijskem Koroškem postaviti ob bok sodobni avstrijski in slovenski umetnosti, revija pa se je prav tako znebila tudi »umetniške estetike preteklega stoletja ter hkrati omogočila slovenskim ustvarjalcem večjo umetniško svobodo in kreativnost« (Kozin 2008: 88).

6 Med večjimi prireditvami naj omenimo njen nastop septembra 2008 pred več tisoč poslušalci na prireditvi City of Asylum v Pittsburghu, v letih 2014 in 2017 je bila gostja knjižnega sejma v Ljubljani, maja 2016 je v organizaciji slovenskega in avstrijskega veleposlaništva brala na avstrijskem veleposlaništvu v Washingtonu D.C. in se predstavila tudi v Knjižnici Ameriškega kongresa (The Library of Congress), leta 2017 pa je gostovala na literarnih večerih v Pragi in na festivalu Vilenica. 


\section{ANALIZA: MIGRACIJE IN TRANSKULTURNOST V ŽIVLJENJU IN DELU CVETKE LIPUŠ}

Cvetka Lipuš se je rodila v Železni Kapli in je hči pisatelja Florjana Lipuša, čeprav se je, kot je v spremni besedi k njeni četrti pesniški zbirki Spregatev milosti zapisal Fabjan Hafner, "sprva komaj opazno, z leti pa vse bolj osvobodila teže imen, zlasti lastnega priimka« (Hafner 2003: b. s.). V okolju, iz katerega izhaja, se je srečevala s številnimi pomembnimi intelektualci slovenskega rodu, kot npr. z Gustavom Janušem, Jankom Messnerjem in Majo Haderlap, hkrati pa živela v okolju, kjer je med njenim odraščanjem in študijem prevladoval nemški jezik. Temu se je po odhodu v Pittsburgh pridružila še lingua franca današnjega sveta, angleščina. Gre torej za večjezično pesnico, ki glede na okolje, delo, sogovornika menja jezike. Značilnost njene večjezičnosti je pravzaprav parcialna, torej »delna večjezičnost« (Kozin 2008: 99), saj je posamezni jezik vedno vezan na določeno obdobje ali na določeno delo ter je zato $v$ ospredju: znanstvene prispevke s področja literarne vede in književnosti največkrat piše $v$ nemščini, medtem ko eseje in strokovne članke objavlja tudi v angleščini. Tako tudi v jezikovnem smislu pušča za seboj transkulturno sled. Ker pa so njeno življenje zaznamovale migracije, sama o sebi meni, da je pravzaprav nekakšna »jezikovna brezdomka« (prav tam: 90). S pisanjem poskuša iz jezika ustvariti prostor, ki obljublja stalno bivališče (prav tam: 91), slednje pa ni nič drugega kot transkulturna geografija življenja in dela pesnice, ki samo sebe dojema kot otroka ne le dveh, slovenske in nemške (Hell 2000: 45-50), temveč treh kultur.

Slovenščina pa je pri Cvetki Lipuš ostala temelj, na katerem je zgradila svoj pesniški opus. To je njen notranji jezik, jezik otroštva, jezik njenih čustev. Vendar pa, kot pravi sama, je treba jezik negovati, sicer zakrni, zato se ji zdi pomembno, da redno prihaja v Slovenijo, saj, kot pravi, je nekako začela pogrešati ta prostor, a ne v geografskem smislu. Pogrešala je predvsem slovenščino, imela je namreč občutek, da se bo popolnoma odtujila, če se ne bo zavestno vračala ne le na Koroško in Dunaj, kjer ima prijatelje, temveč predvsem v Slovenijo (Kondrič Horvat 2008: 27; 2008a: 13). Meni, da se s podobnimi težavami pogosto srečujejo izseljenci in ljudje, ki so »povsod doma", saj je nemogoče, da bi lahko ohranili vse navezave. Bistveno pri tem pa je seveda tudi to, da je slovenščina na avstrijskem Koroškem bolj ali manj omejena na zasebno rabo in ni jezik vsakdanje javne komunikacije.

Če smo se uvodoma spraševali, ali Cvetka Lipuš sebe dojema kot predstavnico manjšine, je treba povedati, da pesnica že od svoje prve pesniške zbirke Pragovi dne$v a(1989)$ ne pristaja na to, da bi jo kritiki in bralci poskušali uokviriti kot koroško, torej manjšinsko avtorico ali kaj podobnega, in dodaja, da ni medij za kakršnokoli manjšinsko potrebo, saj to ni njena stvar (Petrič 2008: 1681). V drugi pesniški zbirki Doba temnjenja (1993) se avtorica manj ukvarja z vprašanji identitete in se raje osredotoča na ljubezenski odnos med človekom in naravo, na neizživete strasti in psihična stanja (Rakusa 1996: 19), medtem ko v tretji zbirki Geografija bližine (2000) z opisovanjem 
eksistencialnih položajev $v$ iskanju prave mere bližine bralcu ponuja načrt za »arhitekturo sožitja, v katerem posameznikovega osebnega prostora ni treba žrtvovati na oltarju skupnosti« (Debeljak 2000: 55). Geografija bližine je izšla leta 2000, ko je bila Cvetka Lipuš že pet let v Ameriki, in zdi se, kot rada pove tudi sama, da ji je najbrž razdalja izostrila čut in pogled, čeprav dodaja, da je razdalja lahko tudi past, kar nekatere zanese v nostalgijo, da vidijo le še delčke in ne več celote. V Geografiji bližine se pesnica sprašuje, kako se približati drugim oziroma drugemu, ne da pri tem izničiš ali podrediš sebe, pri čemer seveda ne moremo spregledati dejstva, da gre za povezavo med pesničino osebno izkušnjo na dvojezičnem ozemlju, kjer se vse ocenjuje skozi prizmo narodne pripadnosti. Gre za pojem, ki bi ga v širšem pomenu lahko zamenjali tudi s pojmom »identiteta«. »Pripadnost, « pravi Cvetka Lipuš, »je v [avstrijskokoroški] stvarnosti bolj ali manj sveta krava. S pripadnostjo se loči zrno od plevela. Lahko si naš, lahko si njihov, ni pa možno, da se kot posameznik postaviš izven teh kategorij« (Kozin 2008: 94).

Tudi obe naslednji zbirki, Spregatev milosti (2003) in Obleganje sreče (2010), sta močno povezani s pesničino transkulturno izkušnjo, saj se je zaradi selitve v Ameriko njeni dvojezični izkušnji pridružila še ameriška, svoje občutke in najglobje misli pa je spet ubesedila v slovenščini. Pri Spregatvi milosti se je osredotočila na več osnovnih tem, ki jih povezuje naslov, mednje pa zagotovo sodita vera in zaupanje, to, čemur bi v angleščini rekli concept of faith, vendar ne v religioznem smislu. Gre bolj za to, »da enostavno verjameš, da obstaja določeno zaupanje, da se bodo stvari končale dobro, da se bo vse uredilo« (Kondrič Horvat 2008: 23). Kot pravi sama, jo je na svoj način presenetil ameriški pogled na stvarnost, zelo pozitiven odnos do vsakdana, ki ni značilen za pesimistične Evropejce. Pesnica izhaja iz lastne izkušnje, ukvarja se s pripadnostjo in ugotavlja, da če si medkulturen, ne moreš pripadati temu ali onemu (prim. Žitnik Serafin 2008; 2011). V tem primeru si del vsega, hkrati pa si »povsod izven, na obrobju, si bežna opomba na robu osrednjega besedila« (Kondrič Horvat 2008: 23).

V Spregatvi milosti se tako dotika skritih in bolečih točk svoje osebne, a tudi širše zgodovine, vendar ne v cankarjanskem smislu, saj se je dokončno osvobodila »jarma koroškosti« (Hafner 2003, b. s.). V nasprotju z zbirko Spregatev milosti predstavlja osrčje Obleganja sreče pesničino novo okolje preko Atlantika. Cvetka Lipuš rada omenja, da že Jeffersonova izjava o neodvisnosti iz leta 1776 vsakomur zagotavlja 'življenje, svobodo in prizadevanje za srečo' (life, liberty and the pursuit of happiness), torej je iskanje sreče $v$ ameriški družbi »fatamorgana, blaženo stanje, $v$ katerem bi naj bil po možnosti človek noč in dan«, in čeprav država ne more zagotoviti osebne oziroma emocionalne sreče, je materialno blagostanje zagotovilo, da se bo slej ko prej pojavila tudi ta (Kondrič Horvat 2008: 23). V pričujoči zbirki jo zanima prav to drugo, torej emocionalna izpolnitev, iskanje sreče, do katere vodijo različne poti. Sicer pa je tudi v teh pesmih navzoča »troedina pripadnost Cvetke Lipuš slovenščini, nemščini in angleščini«, saj njena življenjska izkušnja, kot v oceni zbirke piše Andrej Hočevar, 
»nikakor ni ločljiva od jezika, je izkušnja domač(n)osti in pripadnosti skozi tujost in odtujenost« (2009: 245).

Podobno pesnica tudi v zbirki Pojdimo vezat kosti (2010) »preigrava eno samo strategijo preživetja, ki se v strahu pred ničem oprime upanja« (Petrič 2016: 9), v pesmih prehaja iz kolektivnega v individualno, iz zunanjosti v notranjost, ter ugotavlja, da je življenje ena in edina pot k sebi, pot, ki jo pogojujejo geni, okolje, geografska bližina ali oddaljenost. Prav te plasti, pogojene $z$ biografsko transkulturno izkušnjo, so nanizane tudi v doslej zadnji objavljeni zbirki Kaj smo, ko smo (2015). Ta je nastala v Salzburgu in ponuja odgovor na vprašanje, kaj se skriva pod vsemi plastmi pripadnosti, pod vsem, kar imamo, in prikaže mnogoterno misel o bivanjski danosti vsakega izmed tistih, ki jo beremo (prim. Sagadin 2015: 102-112). Za to delo je pesnica prejela nagrado Prešernovega sklada, David Bandelj pa je v utemeljitvi Cvetko Lipuš iz obrobja postavil v središče, tja, kamor sodi s svojim »široko odprtim svetovljanskim pogledom na svet« (Bilban 2004: 91), kot »živ primer transkulturnosti« (Kondrič Horvat 2016: 71), kot slovensko pesnico $z$ avstrijskim državljanstvom in ameriško izkušnjo:

Težnja raziskovalcev je, da avtorje t. i. obmejnih literatur, kakor je književnost Slovencev v Avstriji, obravnavajo skozi prizmo njihove geografske pripadnosti, ki hočeš nočeš zaznamuje tudi etnično identiteto. ${ }^{7}$ Kljub temu da je Cvetka Lipuš polnopravna članica takega sistema, pa je njegove meje že dodobra presegla in s svojo ustvarjalnostjo sega že močno $v$ slovenski prostor in ga preoblikuje ter prek njega osvaja tudi mednarodni kontekst. Zato je nagrada Prešernovega sklada primerna oddolžitev za táko ustvarjalko, ki v svojem kozmopolitskem duhu biva predvsem $v$ slovenskem jeziku in $v$ njem upesnjuje identitetno mnogoplastnost slehernika. (Bandelj 2016)

\section{RAZPRAVA IN ZAKLJUČEK}

Če zaokrožimo in odgovorimo na prvo vprašanje, kako se transkulturnost, ki je tudi posledica stalnih migracij, kaže pri Cvetki Lipuš oziroma kako kombinacija treh identitet vpliva na njeno ustvarjanje, je odgovor naslednji: Cvetka Lipuš je svetovljanka $s$ transkulturnimi nazori. Njena transkulturnost je utemeljena že v njeni življenjski poti, izkušnjah, selitvah. Številni kraji se menjujejo in jo zaznamujejo, a niso stalnica - stalnica je le jezik njene poezije. Zdi se, kot da je njeno življenje gibanje, ki ji omogoča, da je svobodna, da pusti mislim prosto pot, da razmišlja zunaj okvirov. Njena transkulturna biografija se odraža tudi v njeni poeziji, jezikovno večdomstvo pa je del njenega bitja. In čeprav jo je koroško okolje, predvsem dvojezično odraščanje, zaznamovalo, saj so za štirimi zidovi govorili slovensko, ko pa je prestopila prag hiše, je smuknila v drug jezik, ugotavlja, da v bistvu nikjer ni bila popolnoma doma, ter

7 O nastanku te prim. tudi Vukić in Bara (2013). 
dodaja, da v umetniškem delu ne čuti nobene navezanosti na manjšinsko stvarnost in se tudi ne vključuje $v$ družbeno in politično dogajanje na Koroškem (Kozin 2008: 90). Prav tako v njeni ustvarjalnosti ni mogoče izločiti okvira njene ameriške izkušnje. Cvetka Lipuš spretno kombinira svoje različne identitete tako, da jih spaja. Identitet ne razume kot ločnic, ampak kot presečnice, $v$ okviru katerih lahko poudarja svoje sebstvo kot celoto. $V$ tem okviru se oblikuje tudi njeno ustvarjanje, in sicer predvsem znotraj vseh treh identitet, ki nanj vplivajo sinhrono in simultano.

Glede drugega raziskovalnega vprašanja, ki se je osredotočalo predvsem na to, če (in če da, kako) Cvetka Lipuš v svojem literarnem ustvarjanju zavestno poudarja slovensko komponento, lahko najbolje odgovorimo kar z njenim samoumeščanjem, ko pravi:

Moj mož se je že desetletje pred mano odselil v ZDA, pa se to njegovi nemščini prav nič ne pozna. Seveda so to zavestne odločitve. Nekateri raje zrahljajo navezave in se popolnoma predajo novemu okolju, nekateri pa vztrajajo. Tudi sama sem se zavestno odločila, ko mi je postalo jasno, da bom ostala tam dalj časa, za to jezikovno navezavo. Začelo me je malce skrbeti, da se mi bo živ govor bolj ali manj odtujil. Saj se včasih izseljencem po govorici sliši, kdaj so se odselili. V Slovenijo pa sem se začela vračati predvsem zato, ker na Koroškem prevladuje nemščina. Na avstrijskem Koroškem je slovenččina bolj ali manj jezik privatnega življenja in ne javne vsakdanje komunikacije. Moja vsakodnevna jezikovna izkušnja je sedaj popolnoma angleška in bi želela, da je za nekaj časa popolnoma slovenska. V Ljubljano pa rada pridem, ker mi je bolj ali manj domača, a ne preveč, saj tukaj nikoli nisem živela in je zame dovolj zanimivo in novo mesto, da ostanem mesec dni. (Kondrič Horvat 2008: 27)

Iz navedenega izhaja, da Cvetka Lipuš svoj odnos do slovenščine gradi zavestno, tega odnosa pa ne povezuje z odnosom do Slovenije. Ugotovimo lahko, da je slovenščina del njene identitete, Slovenija (kot država) pa ne. Tako kot se identitetno ne počuti manjšinka, tako se tudi nima za Slovenko ( $v$ smislu nacije). Počuti pa se kot slovenska pesnica ( $v$ smislu narodnosti). To nazorno ponazori sama $v$ verzu iz cikla Za trenutek v istem telesu iz Geografije bližine, kjer zapiše: „Občasno si nekdo prizna, kdor išče dom v sebi, ni brezdomski« (Lipuš 2000: 45). To je ambivalentnost, ki pomirja in vznemirja obenem, kajti, kot na nekem drugem mestu pravi pesnica: »Brezdomski, udomiš se v lesket zvezd« (prav tam: 20). Cvetka Lipuš pravi, da nikoli ni čutila posebne navezanosti na določen prostor, geografsko območje, na to, kar imenujemo domovina. Vsakršna zagledanost $v$ nacionalne mite in nacionalno pripadnost jo je vedno odbijala, saj gre za vprašanje vključevanja in izključevanja; medtem ko so nekateri (domačini) avtomatično vključeni, so drugi (priseljenci) izključeni (prim. Hall 1996). A čeprav smo družabna bitja in se radi stisnemo skupaj, se trepljamo po ramenih in si ob narodnih ali drugih družabnih manifestacijah patriotsko pritrjujemo, kako posebni smo, »ima ta vzajemnost svojo ceno, saj zahteva podreditev lastnih prepričanj in ambicij vrednotam določene družbe« (Kondrič Horvat 2008: 27). 
To je sebstvo, ki vključuje večdomovinskost Cvetke Lipuš. Sogovornik dobi občutek, da je ta večdomovinskost prav tisto, kar njenemu delu daje posebnost - je hkrati vse in nič. Nikjer se ne udomači ali ukorenini (v geografskem in časovnem prostoru). Sama sebe definira skozi jezik, skozi to, kar je, in to, kar se v svoji stalnosti ves čas spreminja. Zato vedno znova išče nove, začasne in nadčasne (geografske) prostore, ki ji omogočajo nove začetke oziroma, kot pravi sama: „Skozi svojo celotno pisateljsko kariero sem v zemljevide vrisovala tako resnična kot izmišljena ozemlja pripadnosti« (Lipuš 2010: 117; prim. tudi Lipuš 2016: 61). K pisanju je torej ni spodbudilo neko domoljubje ali opisovanje koroške izkušnje - s čimer se deloma ukvarja v esejih - ampak veselje do branja in veselje do lastnega umetniškega izražanja. Čeprav je živela in se izobraževala v Avstriji in ZDA, je zanjo slej ko prej samoumevno, da poezijo piše v slovenščini, eseje pa v nemščini in angleščini. V enem od esejev z naslovom Writing in Between (Lipuš 2016) ${ }^{8}$ sama poudarja, da nikoli ni želela biti glasnik svojega plemena, ki je kot slovenska manjšina živelo na avstrijsko-slovenski meji, pa tudi ne glasnik Slovencev v Sloveniji, obenem pa meni, da je jezik globoko vtkan v njeno mišljenje, v njene socialne in politične odnose in v njeno psiho (prim. o tem Zlatnar Moe in Grahek Križnar 2012: 71-90). Materinščino povezuje z izkušnjami iz otroštva, s spomini in z občutki, ki jih povezujemo s svojimi primarnimi odnosi (prim. tudi Petrič 2015: 16).

A tudi drugi in tretji jezik ji nista breme oziroma ju ne občuti kot pritisk, temveč kot dodano vrednost, omogočata ji, tako kot je to značilno za vsak nadaljnji jezik, da se ji odpirajo nova obzorja in dovoljujejo, da vstopa v nove prostore in nove oblike izražanja. Zanimiv je tudi njen odnos do nemškega jezika - sploh glede na to, da je v tem jeziku odrasla zunaj domačih zidov. Kot poudarja sama, ji nemščina nikoli ni bila blizu, saj je bila v njenem svetu jezik tistih, ki so veliko prebivalcev njene doline deportirali v taborišča. A to se je prelomilo med študijem in nato življenjem v nemščini, ko je nemščino začela razumeti ne kot omejitev, ampak kot osvoboditev. Z nemščino je namreč zgradila most do drugih pisateljev in do literarne tradicije, ki ji je bila vsaj tako blizu kot slovenska. Šele tedaj jo je zavestno sprejela in ji je postalo jasno, da se ne more omejiti ne geografsko ne jezikovno. Edina omejitev, ki jo je od takrat razumela, je bila funkcionalna omejitev, tj. vprašanje, kako dosegati tisto, kar si želiš. Jezik je v tem okviru postal sredstvo za doseganje ciljev. Ta prelom pa je pomenil še drugačno razumevanje, in sicer, da je wittgensteinovska napoved »meje mojega jezika so meje mojega sveta« pomembna ne samo za pripadnike matičnega naroda, ampak za celoten sistem narodov in civilizacij, ki jim kot posameznik pripadaš. Zato ne preseneča, da Cvetka Lipuš sama poudarja, da ne želi pripadati nobeni smeri ali literarnemu krogu (Borovnik 2006: 438), prav tako pa nikakor noče, da se jo označuje kot zamejsko pesnico, saj gre za klasifikacijo, ki je nastala v osrednji Slovenji, kjer literarna stroka pisatelje in pesnike zelo rada prišteva

8 Ker je šlo prvotno za predavanje, je slovenski prevod z naslovom Pisati nekje vmes izšel že prej (Lipuš 2010). 
$k$ določenim pokrajinam in njihove značilnosti mnogokrat tudi poistoveti s pisateljem. Prav tako v izrazu »manjšinski« prepozna kategorijo marginalnosti in obrobja, kar po njenem pomeni le opombo pod črto $v$ kanonu slovenske književnosti.

$V$ današnjem svetu in času, ko se po eni strani soočamo z globalizacijo, po drugi pa s partikularizacijo, najdemo predvsem $v$ literarnih delih veliko elementov transnacionalnega in transkulturnega, $s$ katerimi se pisatelji in pisateljice $v$ svojih subverzivnih delih upirajo ustaljenim (običajno binarnim) miselnim in jezikovnim vzorcem ter vzorcem obnašanja, ki jih navadno določa središče. Transkulturnost identitet se v literarnih delih pojavi pri ustvarjalcih, ki imajo bi- ali plurikulturne življenjepise in ki z literarnimi besedili, ki jih razumemo kot demonstratorje kulturne različnosti, omogočajo širjenje in razširjanje znanja o razumevanju in razlikah med kulturami, kar hkrati omogoča tudi ohranjanje in spodbujanje kulturne pestrosti. V to skupino nedvomno sodi tudi Cvetka Lipuš, ki v svoja lirična besedila vpleta osebne izkušnje in čutenja in jih z njimi prepleta, kakor tudi z izkušnjami iz svojih treh domovin, ki so jo zaznamovale, svojo primarno kulturo povezuje s kulturo dežele, v kateri živi.

Sklenemo lahko, da smemo pri Cvetki Lipuš govoriti o transverzalnem umu (Welsch 1995/2000), bistvo njene poezije pa je transkulturno, kar pomeni, da so obzorja njene poezije neomejena, vsak dodatni identitetni del v kulturi pa sama razume predvsem kot širino in ne kot omejitev. Prav to je pri njej, ki jo je že od nekdaj motila ozkost, zelo očitno. Tako jo je na primer med bivanjem na Koroškem pri koroških Slovencih motila konservativnost, saj je v zatohlem družbenem ozračju, kjer se je o vojnih izkušnjah dolgo molčalo, pogrešala odprtost. In tudi v Sloveniji ni bilo nič drugače. ${ }^{9}$

Z vidika ustvarjanja in oblikovanja slovenskega naroda ter prevladujoče teorije razvoja slovenskih manjšin je Cvetka Lipuš izjema. Ideje, da je treba manjšine zaščititi, ker trpijo že zato, ker so odrezane od matice, Cvetka Lipuš ni nikoli ponotranjila. Slovenski jezik zanjo nikoli ni bil cilj sam po sebi, ampak sredstvo za njeno bivanje, umevanje in ustvarjanje. Zato je logično, da ji ne moremo nadeti nalepke zamejska/ manjšinska pesnica - ne le, ker se opremljena s takšno etiketo ne počuti dobro, temveč predvsem zato, ker bi s tem izrazili svojo omejenost in geografsko pozicioniranje izrazili z oholostjo. Kajti označiti nekoga za manjšino, pomeni le, da imaš sebe za pripadnika večine in da imaš zato per definitionem več pravic in boljši status. Končno je treba ugotoviti, da moramo tudi njeno poezijo brati predvsem v okviru njenega svetovljanstva in transkulturnosti, ki jo resda definira v prvi vrsti slovenski jezik, a drugi dve izkušnji (avstrijska in ameriška) štejeta kot obogatitev njenega sebstva in bistva.

9 V stik s Slovenijo je intenzivneje prišla v začetku osemdesetih let prejšnjega stoletja, ko je izšla njena prva samostojna zbirka, a v Slovenijo je hodila bolj poredko, saj je bolj samotarske narave, in drugič, pravi, so ji bile nekatere značilnosti osrednje slovenske družbe preveč konservativne. 


\section{LITERATURA}

Arbeiter, Jana, Udovič, Boštjan (2017). Does the Mediterranean Exist in States' Diplomatic Rituals?: A Comparison of Mediterranean States' Préséance. International Journal of Euro-Mediterranean studies 10/2, 79-106.

Bandelj, David (2016). Pesnica Cvetka Lipuš. Almanah Prešernove nagrade 2016, http:// www.mk.gov.si/fileadmin/mk.gov.si/pageuploads/Ministrstvo/o_ministrstvu/ Presernov_sklad/2016/2016_ALMANAH_PRESERNOVE_NAGRADE.pdf (5. 5. 2019). Bhabha, Homi K. (2000). Die Verortung der Kultur. Tübingen: Stauffenburg Verlag.

Bilban, Tina (2004). Cvetka Lipuš: Spregatev milosti. Ampak: Mesečnik za kulturo, politiko in gospodarstvo 8/9, 91-92.

Borovnik, Silvija (2006). Slovenske književnice v Avstriji. Slavistična revija 54/3, 431-442.

Debeljak, Aleš (2000). Spremna beseda. V: Cvetka Lipuš: Geografija bližine. Celovec: Wieser, 55.

Durnik, Mitja (2017). Slovenian Migrants and the Ethnic Economy in Contemporary Canada. Dve domovini / Two Homelands 46, 103-118.

Durnik, Mitja, Gombač, Jure (2012). Theorizing the Potential of Political Economy and Social Economy Approaches in Studying the Structure of Ethnic Economies. Dve domovini / Two Homelands 35, 119-133.

Hafner, Fabjan (2003). Kako naj razložim in utemeljim [...] (Spremna beseda na zavihkih). V: Cvetka Lipuš: Spregatev milosti. Ljubljana: Cankarjeva založba, nepag.

Hall, Stuart (1996). Who Needs Identity? Questions of Cultural Identity (ur. Stuart Hall, Paul du Gay). London, Thousand Oaks, New Delhi: SAGE Publications, 1-17.

Hell, Cornelius (2000): Leben und Schreiben in zwei Sprachen: Splitter zur slowenischen Literatur in Kärnten. Literatur und Kritik 341/342, 45-50.

Hočevar, Andrej (2009). Čustveno z okvirom. Literatura 21/215-216, 243-250.

Hoerder, Dirk (2012). Belonging, Membership, and Mobility in Global History. Dve domovini / Two Homelands 35, 97-105.

Jurić Pahor, Marija (2012a). Čezmejni in transkulturni imaginariji: Alpsko-jadranski prostor v kontekstu njegovega zamišljanja in o(d)smišljanja. Annales: Anali za istrske in mediteranske študije, Series historia et sociologia 22/2, 409-424.

Jurić Pahor, Marija (2012b). Transkulturacija in kulturna hibridnost: Dva ključna pojma postkolonialnih študijev kot izziv za proučevanje nacionalnih in etničnih identitet. Razprave in gradivo: Revija za narodnostna vprašanja 69, 36-65.

Jurić Pahor, Marija (2015a). Od starih k novim imaginarijem pripadanja: Nacionalna in etična identiteta onkraj binarnih o/pozicij. Annales: Anali za istrske in mediteranske študije. Series historia et sociologia 25/1, 183-196.

Jurić Pahor, Marija (2015b). Univerza kot transnacionalni in transkulturni prostor: Razmislek o porajajoči se »eliti znanja«. Dve domovini / Two Homelands 4, 139-150. 
Jurić Pahor, Marija (2018). Transkulturnost in kulturna hibridnost v kontekstu migracij: Primer mesta Trst. Annales: Anali za istrske in mediteranske študije. Series historia et sociologia 28/1, 51-64.

Kočan, Faris, Arbeiter, Jana (2019). TIKA Turkey's Platform for Development Cooperation or Something More?: Evidence from the Western Balkans. International Journal of Euro-Mediterranean studies 12/1, 167-193.

Kondrič Horvat, Vesna (2008). Če se ne bom zavestno vračala v Slovenijo, se bom odtujila: Pogovor s Cvetko Lipuš. Ampak: Mesečnik za kulturo, politiko in gospodarstvo 9/10, 22-27.

Kondrič Horvat, Vesna (2008a). »O, kako dobro govorite nemško. Ja kdaj ste se pa priselili?«: O medkulturnosti s pesnico Cvetko Lipuš. Večer 64/173, 28. julij 2008, 13.

Kondrič Horvat, Vesna (2016). A Bittersweet Homecoming: An Interview with Cvetka Lipuš in Washington, D.C., 20. maj 2016. Slovene Studies 38/1-2, 71-78.

Kozin, Tina (2008). Po naravi sem sezonsko družabno bitje z dolgimi fazami osame: Pogovor s Cvetko Lipuš. Literatura 20/210, 88-105.

Lipuš, Cvetka, Hafner, Fabjan (ur.) (1985): V lunini senci. Celovec: Drava.

Lipuš, Cvetka (1989). Pragovi dneva. Celovec: Wieser

Lipuš, Cvetka (1993). Doba temnenja. Celovec/Salzburg: Wieser.

Lipuš, Cvetka (2000). Geografija bližine. Celovec: Wieser.

Lipuš, Cvetka (2003). Spregatev milosti. Ljubljana: Cankarjeva založba.

Lipuš, Cvetka (2008). Obleganje sreče. Ljubljana: Cankarjeva založba.

Lipuš, Cvetka (2010). Pojdimo vezat kosti. Ljubljana: Mladinska knjiga.

Lipuš, Cvetka (2010). Pisati nekje vmes (prevedel Andrej Hočevar). Literatura 22/223$224,117-127$.

Lipuš, Cvetka (2015). Kaj smo, ko smo. Ljubljana: Beletrina.

Lipuš, Cvetka (2016). Writing in Between. Slovene Studies 38/1-2, 61-69.

Lukšič Hacin, Marina, Toplak, Kristina (2012). Teoretizacija multikulturalizma in etnične ekonomije v luči ohranjanja kulturne dediščine med migranti. Dve domovini / Two Homelands 35, 107-117.

Lukšič Hacin, Marina (2016). Theorizing the Concept of Multiculturalism through Taylor's 'Politics of Recognition'. Dve domovini / Two Homelands 44, 79-91.

Milharčič Hladnik, Mirjam (2007). Avto/biografičnost narativnosti: Metodološko teoretični pristopi v raziskovanju migracijskih izkušenj. Dve domovini / Two Homelands 26, 31-46.

Milharčič Hladnik, Mirjam (2015). Kultura mešanosti v nacionalnem in migracijskem kontekstu. Annales: Anali za istrske in mediteranske študije, Series historia et sociologia 25/1, 171-182.

Novak Popov, Irena (ur.) (2007). Antologija slovenskih pesnic 3 (1981-2000). Ljubljana: Tuma.

Petrič, Tanja (2008). Cvetka Lipuš: Obleganje sreče. Sodobnost 72/11-12, 1681-1685.

Petrič, Tanja (2015). Če bi bila rojena v Španiji, bi bila španska pesnica. Pogledi 6/12, 16. Petrič, Tanja (2016). Med vsakdanom in vesoljem: Cvetka Lipuš, pesnica. Pogledi 7/3, 9. 
Pišek, Mojca (2016). Cvetka Lipuš: Ko hodim po Ljubljani, mi slovenščina zveni drugače kot vam. Dnevnik, 29. marec 2016, https://www.dnevnik.si/1042732722 (20. 4. 2019).

Poniž, Denis (2001). Slovenska lirika 1950-2000. Ljubljana: Slovenska matica.

Rakusa, IIma (1996): Gedichte von Cvetka Lipuš. Neue Zürcher Zeitung, 5. februar 1996, 19.

Repič, Jaka (2006). »Po sledovih korenin«: Transnacionalne migracije med Argentino in Evropo. Univerza v Ljubljani, Filozofska fakulteta, Oddelek za etnologijo in kulturno antropologijo.

Repič, Jaka (2010). Ambivalent Identities Emerging in Transnational Migrations between Argentina and Slovenia. Dve domovini / Two Homelands 31, 121-134.

Sagadin, Vid (2015). Dramatični telesni performans. V: Cvetka Lipuš: Kaj smo, ko smo. Ljubljana: Beletrina, 103-112.

Strutz, Johann (ur.) (1998). Profile der neueren slowenischen Literatur in Kärnten. Celovec: Mohorjeva založba.

Valentinčič, Dejan (2016). Vračanje potomcev slovenskih izseljencev v ZDA in Kanadi k slovenski identiteti v kontekstu globalnega trenda individualizacije. Dve domovini / Two Homelands 44, 153-166.

Vincetič, Milan (2015). Cvetka Lipuš: Kaj smo, ko smo. Sodobnost 79/6, 763-765.

Vukić, Aleksandar, Bara, Mario (2013). The Importance of Observation, Classification and Description in the Construction of the Ethnic Identity of Bunjevci from Bačka (1851-1910). Dve domovini / Two Homelands 37, 69-81.

Welsch, Wofgang (1995/2000). Vernunft: Die zeitgenössische Vernunftkritik und das Konzept der transversalen Vernunft. Frankfurt na Majni: Suhrkamp.

Welsch, Wofgang (1997). Transkulturalität: Zur veränderten Verfassung heutiger Kulturen. Hybridkultur: Medien, Netze, Künste (ur. Irmela Schneider, Christian Werner Thomsen). Köln: Wienand Verlag, 67-90.

Welsch, Wofgang (1999). Transculturality - the Puzzling Form of Cultures Today. Spaces of Cultur: City, Nation, Word (ur. Mike Featherstone, Lash Scott). London: Sage Publications, 194-213.

Zadel, Maja (2016). Vloga italijanskih medijskih vsebin pri oblikovanju transkulturnih identitet na območju slovenske Istre. Doktorska disertacija. Koper: Univerza na Primorskem, Fakulteta za humanistične študije.

Zlatnar Moe, Marija, Grahek Križnar, Nina (2012). The Influence of Ideological Orientation on Target Language Text Production. The Interpreter and Translator Trainer 6/1, 71-90.

Zupančič, Jernej (1997). Slovenci v Avstriji: Število, način poselitve, struktura, identiteta. Geografski vestnik 69, 115-138.

Zupančič, Rok, Arbeiter, Jana (2016). Primitive, Cruel and Blood-thirsty Savages: Stereotypes in and about the Western Balkans. Teorija in praksa 53/5, 1051-1063.

Žigon, Zvone (2018). Med poslom in domoljubjem: Etnična ekonomija in Slovenci zunaj Republike Slovenije. Dve domovini / Two Homelands 47, 127-145. 
Žitnik Serafin, Janja (2008). Večkulturna Slovenija: Položaj migrantske književnosti in kulture v slovenskem prostoru. Ljubljana: ZRC SAZU.

Žitnik Serafin, Janja (2011). Literarna zapuščina slovenskih izseljencev $v$ drugih deželah Evrope. Dve domovini / Two Homelands 34, 35-45.

Žitnik Serafin, Janja (2014). Vloga izseljenske/priseljenske književnosti in literarne vede pri raziskovanju migracij. Dve domovini / Two Homelands 39, 31-42. 


\section{SUMMARY}

\section{QUESTIONS OF IDENTITY, MIGRATIONS AND TRANSCULTURALITY: THE CASE OF THE POET CVETKA LIPUŠ Tanja ŽIGON, Vesna KONDRIČ HORVAT, Boštjan UDOVIČ}

The paper presents a case study of the internationally acclaimed and multi-awardwinning poet Cvetka Lipuš. Her life and work have been influenced by three languages and cultures, Slovenian, German and English. The paper deals with two research questions. First, we discuss how transculturality, caused among other things by her constant migrations, is manifested in her work, how the poet addresses the three identities that define her, and how this combination of three identities and three homelands affects her work. Second, we ask whether Lipuš intentionally emphasizes her Slovenian identity in her literary works, and whether this identity is an inherent part of her essence and as such a part of her unconscious. The article is based on an analysis of accessible primary and secondary sources (interviews with and public appearances by Cvetka Lipuš in Slovenian print or audio-visual media). This analysis is complemented by results obtained through a combination of semi-structured and unstructured interviews which we conducted with the poet. On the basis of the data we reviewed and evaluated, we can conclude that Lipuš is a cosmopolitan who stands for transculturality, a stance that is rooted in her life path, experiences, and migration. She has lived in and been influenced by many places, but none of them function as a constant; her only constant is the Slovenian language, i.e. the language of her poetry. Her transcultural biography is also reflected in her poems, and multilingual affiliation is an inherent part of her. As a poet, she is neither limited by geographical boundaries nor by those of language and culture. Therefore, it is not surprising that Lipuš herself stresses that she does not wish to belong to any literary movement or group. She has no wish to be labelled as a minority poet, since this is a marginal category. Cvetka Lipuš has crossed national boundaries and shaped her identity within a supranational, international or global frame. This means that she does not conform to any boundaries and does not belong to any category (but rejects them). Her work is influenced in the highest degree by her identity as a person with multiple homelands. Thus, her sense of belonging is not linked to established political and sociological concepts such as ethnicity, nation, or nation-state. Cvetka Lipuš is also an exception within the framework of the formation and development of the Slovenian nation, as well as in connection with the prevalent theory on the evolution of the Slovenian minority. She has never internalised the idea that minorities should be protected because they live outside their homeland and thus suffer by default. For her, the Slovenian language has never been an end in itself but in fact a vehicle for living, thinking and writing. 